board than those of Hansen, and so there is a better chance of correcting the errors, which no mortal can altogether escape. Next the constants are not stereotyped, and if it is necessary to change them the effect can be made visible; and for a searching piece of evidence, Prof. Brown has shown already that his calculations remove the last shred of disagreement between the calculated and observed motions of the moon's apse. Finally, in a recent analysis of the Greenwich observations back to $1750, \mathrm{Mr}$. P. H. Cowell has given a most striking verification of all Prof. Brown's coefficients.

When Prof. Brown constructs his tables there is an error Hansen fell into which he may be trusted to avoid. In order to improve the agreement with observation, Hansen introduced a certain empirical element. An empirical correction is better than nothing, but it cannot be too clearly recognised that until it is furnished with a theoretical basis it is no more than a mathematical memoria technica. Certainly its place is not in a set of tables, the sole function of which is to expose correctly and fully the consequences of a clear theory and definite elements, with the view of testing the one and amending the others.

R. A. S

\section{THE CONTROL OF THE GAS SUPPLY OF THE METROPOLIS.}

THE notification of the metropolitan gas referees just issued differs in several respects from that for the preceding year, a change necessitated by the provisions of the London Gas Act, 1905. For some years past the London gas companies have been asking for the revision of their Acts, with reference more especially to the system of testing to which their gas is subjected. In the early days of gas supply, when there was free competition and the consumer had the choice of more than one company, no testing was regarded as necessary, but when, owing to the amalgamation and consolidation of the gas companies, the supply became a monopoly, a system of testing the purity and illuminating power of the gas was instituted. The whole of the arrangements for testing London gas, with the exception of one or two points specially laid down in some of the Acts, are left to the discretion of the gas referees, originally appointed under the City of London Gas Act, r868. It was alleged by the companies that the requirements of the referees were too stringent and out of touch with the modern developments of gas manufacture. In January, I904, a departmental committee of the Board of Trade was appointed to inquire and report as to the whole system of gas-testing in the metropolis. At the inquiry the committee heard evidence from the gas referees, and from representatives of the London County Council, the Corporation of London, and each of the three gas companies concerned. It is noteworthy that no actual consumer was heard, although on one of the most important points dealt with by the committee, the question of sulphur impurity, the committee in its report says, "It does not appear that any complaints are made by the inhabitants of other districts on the ground that the gas thus unpurified causes injury to health or is more destructive to articles such as leather, \&c., than it is supposed to be in London."

The report of the committee was almost wholly favourable to the companies. The mode of testing for sulphuretted hydrogen is to be relaxed, a test lasting three minutes being substituted for one spread over Is hours, and all sulphur compounds other than sulphuretted hydrogen may be, and henceforth will be, left in the gas. The evidence of the companies as to No. I 890 , roL. 73$]$ the amount of sulphur impurity under the new conditions was to the effect that an average of 35 grains per $100 \mathrm{c}$.ft. or under might be expected, with the possibility of an occasional rise to 40 , the maximum under the Acts just repealed being 17 grains in summer and 22 grains in winter. The figures for the amount of sulphur present in the gas supplied by the South Metropolitan Company during December last throw a: instructive light on the value of this evidence, the weekly average increasing from 40.8 to 44.6 grains per roo c.ft. with a single maximum of $61 \cdot 3$. On one occasion the Commercial Gas Company surpassed even this figure with a maximum of 70.2 . It is clear, therefore, that the gas now to be supplied to London may contain about double the amount of sulphur contemplated by the departmental committee, and this is of interest in view of the fact that a Bill is now before Parliament promulgated by various provincial gas companies asking to be placed in the same position as the London companies as regards the removal of sulphur restrictions.

In one point the report of the departmental committee was favourable to the consumer. It recommended that the standard burner for testing the illuminating power of all qualities of gas should be the burner at present in use, the Sugg's London Argand No. I, the gas to be burnt at the rate of five feet per hour. The gas referees in their present notification disregard this recommendation, and prescribe a burner devised by the engineer to the South Metropolitan Gas Company. The practical effect of this will be to increase the nominal illuminating power of the gas supplied by those companies having a r4-candle standard. It will be seen, therefore, that the new conditions are wholly favourable to the companies.

There remains one new point in the gas referees' notification, the prescription of a method of determining the calorific power of gas. The calorimeter, which has been devised by Mr. C. V. Boys, appears to be a distinct advance over its predecessors of the same type, and when it is installed in the testing stations systematic measurements of the ealorific power of London gas will, for the first time, be on record, and will be available for the next battle on the gas question, calorific power $v$. illuminating power.

\section{PROF. C. J. JOLY, F.R.S.}

THE lamentable death of Prof. C. J. Joly at the early age of forty-one closes a career which was likely to influence favourably the mathematical side of astronomy. But his tenancy of the post of Royal Astronomer of Ireland and Andrews Professor in the University of Dublin was, alas! too short for him to make his individuality felt in the science with which he was connected by his occupancy of the chair, that has of late been held by Sir Robert Ball and Dr. Arthur Rambaut. The traditions of the office, and it may be the interrupted work of these astronomers, would naturally compel him for a time to follow certain definite lines which the previous occupants of the chair had approved. But his work in the department of pure and applied mathematics was of a high order and affords abundant evidence of originality and capacity.

From the time that Prof. Joly entered Trinity College, Dublin, his academic career was marked by his devotion to natural science, and mathematical scholarships and studentships were the natural preliminaries that led to a later fellowship. In this position he distinguished himself as a successful teacher of advanced science, but in 1897 , when Dr. Arthur Rambaut was appointed to the office of Radcliffe observer, Dr. Joly 